\title{
Neurofibromin-deficient Schwann cells secrete a potent migratory stimulus for $\mathrm{Nf1}^{+/-}$mast cells
}

\author{
Feng-Chun Yang, ${ }^{1,2}$ David A. Ingram, ${ }^{1,2,3}$ Shi Chen, ${ }^{1,2}$ Cynthia M. Hingtgen, ${ }^{4}$ \\ Nancy Ratner, ${ }^{5,6}$ Kelly R. Monk, ${ }^{5,6}$ Travis Clegg, ${ }^{1,2}$ Hilary White, ${ }^{1,2}$ Laura Mead, ${ }^{1,2}$ \\ Mary Jo Wenning, ${ }^{1,2}$ David A. Williams, ${ }^{7}$ Reuben Kapur, ${ }^{1,2}$ Simon J. Atkinson,, ${ }^{3,8}$ \\ and D. Wade Clapp ${ }^{1,2,9}$ \\ ${ }^{1}$ Department of Pediatrics, \\ ${ }^{2}$ Herman B. Wells Center for Pediatric Research, \\ ${ }^{3}$ Department of Biochemistry and Molecular Biology, \\ ${ }^{4}$ Department of Neurology and Pharmacology, Indiana University School of Medicine, Indianapolis, Indiana, USA \\ ${ }^{5}$ Department of Cell Biology and \\ ${ }^{6}$ Department of Neurobiology \& Anatomy, University of Cincinnati College of Medicine, Cincinnati, Ohio, USA \\ ${ }^{7}$ Division of Experimental Hematology, Cincinnati Children's Hospital Medical Center, Cincinnati, Ohio, USA \\ ${ }^{8}$ Department of Medicine and \\ ${ }^{9}$ Department of Microbiology and Immunology, Indiana University School of Medicine, Indianapolis, Indiana, USA
}

The NF1 tumor suppressor gene encodes a GTPase-activating protein called neurofibromin that negatively regulates Ras signaling. Mutations in NF1 cause neurofibromatosis type 1 (NF1). The development of neurofibromas, which are complex tumors composed of multiple cell types, is a hallmark of NF1. Somatic inactivation of murine Nf1 in Schwann cells is necessary, but not sufficient, to initiate neurofibroma formation. Neurofibromas occur with high penetrance in mice in which Nf1 is ablated in Schwann cells in the context of a heterozygous mutant $\left(\mathrm{Nf1}^{+/-}\right)$microenvironment. Mast cells infiltrate neurofibromas, where they secrete proteins that can remodel the ECM and initiate angiogenesis. Thus, identification of mechanisms responsible for mast cell migration to tumor microenvironments is important for understanding tumorigenesis and for designing potential therapies. Here, we show that homozygous $N f 1$ mutant $\left(\mathrm{Nf}^{-/-}\right)$Schwann cells secrete Kit ligand (KitL), which stimulates mast cell migration, and that $\mathrm{Nf1}^{+/-}$mast cells are hypermotile in response to KitL. Furthermore, we link hyperactivation of the Ras-class $\mathrm{I}_{\mathrm{A}}$-PI3K-Rac2 pathway to increased $\mathrm{Nf1}^{+/-}$mast cell migration. Thus, these studies identify a novel interaction between $\mathrm{Nf1}^{-/-}$Schwann cells and $\mathrm{Nf1}^{+/-}$ mast cells that is likely to be important in neurofibroma formation.

J. Clin. Invest. 112:1851-1861 (2003). doi:10.1172/JCI200319195.

Received for publication June 12, 2003, and accepted in revised form October 7, 2003

Address correspondence to: D. Wade Clapp,

Indiana University School of Medicine, Cancer Research Institute, 1044 West Walnut Street, R4/470, Indianapolis, Indiana 46202, USA.

Phone: (317) 274-4719; Fax: (317) 274-8679;

E-mail: dclapp@iupui.edu.

Feng-Chun Yang and David A. Ingram contributed equally to this work.

Conflict of interest: The authors have declared that no conflict of interest exists.

Nonstandard abbreviations used: neurofibromatosis type 1 (NF1); GTPase-activating protein (GAP); kit ligand (KitL); nerve growth factor (NGF); white-spotted locus (W); bone marrow-derived mast cell (BMMC); fetal liver-derived mast cell (FLMC); dorsal root ganglia (DRG); recombinant human glial growth factor 2 (rhGGF2); conditioned media (CM); phycoerythrin (PE); virus expressing the full-length NF1 GTPase-activating related domain (NF1 GRD); virus expressing the full-length NF1 GRD pac (MSCV-NF1 GRD-pac); virus expressing the selectable marker gene alone (MSCV-pac); fibronectin (FN);

filamentous actin (F-actin); monocyte chemotactic factor 1 (MCP-1); receptor tyrosine kinase (RTK); recombinant murine KitL (rmKitL).

\section{Introduction}

Mutations in the NF1 tumor suppressor gene cause neurofibromatosis type 1 (NF1), a pandemic autosomal dominant genetic disorder with an incidence of 1:3,500 people (1). Neurofibromin, the protein encoded by NF1, functions as a GTPase-activating protein (GAP) for Ras by accelerating the hydrolysis of active Ras-GTP to an inactive Ras-GDP $(2,3)$. Cutaneous and plexiform neurofibromas are pathognomonic for NF1 and constitute a major source of morbidity in NF1 patients. Currently, there are no medical treatments to prevent or diminish neurofibroma growth.

Neurofibromas are characterized by excessive ECM deposition and close cellular associations among the multiple cell types within the tumors, including Schwann cells, fibroblasts, endothelial cells, and mast cells (4-6). While the pathogenesis of neurofibroma formation is incompletely understood, investigators have hypothesized that inflammatory mast cells may have a role in the progression of tumor formation (1) and have shown that neurofibromas have much higher concentrations of mast cells within the tumor as compared 
with adjacent areas of skin $(1,6,7)$. In addition, recent important insights have been gained by analyzing genetically engineered mice that develop plexiform neurofibromas (8). In these studies, conditional deletion of both Nf1 alleles in murine Schwann cells was necessary but not sufficient to generate neurofibromas (8). When mice harboring a conditional deletion of $N f 1$ in Schwann cells were backcrossed onto an Nf1 heterozygous background, however, the animals uniformly developed neurofibromas that closely resembled human neurofibromas, including dense mast cell infiltrations (8). These genetic studies demonstrate the essential function of $N f 1$ heterozygous cells in neurofibroma formation and the importance of understanding the basic mechanisms of how these cells are recruited to and function within the tumor microenvironment.

Recent studies demonstrate that inflammation is a critical component of tumor initiation and progression (reviewed in refs. 9-11). Many cancers arise from sites of chronic irritation and inflammation (11). It is evident that the tumor microenvironment and the initiation of angiogenesis, which is largely orchestrated by inflammatory cells, is an indispensable participant in the neoplastic process $(9,10)$. The mechanisms that control the recruitment of inflammatory cells to tumor microenvironments, especially in neurofibroma formation, are poorly understood, however.

We have previously shown that $\mathrm{Nf}^{+/-}$inflammatory mast cells have increased proliferation and survival in response to Kit ligand (KitL) both in vitro and in vivo $(12,13)$. Furthermore, $\mathrm{Nf}^{++-}$mice have increased numbers of cutaneous and peritoneal mast cells $(12,13)$. Interestingly, mast cells increase dramatically in peripheral nerve injury and repair (14), Schwann cell neoplasias (6), and other cutaneous tumors (15-17). Mast cells can secrete both nerve growth factor (NGF) (18) and VEGF (19-21), which are potent stimulants for Schwann cell proliferation, migration, and survival (21). While these studies clearly define an interaction between mast cells and Schwann cells, it remains unclear how mast cells are recruited to Schwann cells and peripheral nerves.

Given the potential importance of mast cell-Schwann cell interactions and inflammation within the tumor microenvironment for neurofibroma formation, we designed experiments to test whether $\mathrm{Nf1}^{-/-}$Schwann cells secrete chemotactic factors for mast cell migration. Furthermore, based on our previous studies, we tested whether $\mathrm{Nf1}^{+/-}$mast cells were hypersensitive to chemotactic factors secreted by $\mathrm{Nf1}^{-/-}$Schwann cells.

Here we provide genetic and biochemical evidence that loss of the $N f 1$ tumor suppressor gene in Schwann cells provides a potent chemotactic stimulus for $\mathrm{Nf1}^{+/-}$ mast cells through secretion of soluble KitL and activation of a specific Ras effector-signaling pathway.

\section{Methods}

Animals. $\mathrm{N1}^{+/-}$mice were obtained from Tyler Jacks at the Massachusetts Institute of Technology (Cambridge, Massachusetts, USA) in a C57BL/6J.129 background and backcrossed for 13 generations into a C57BL/6J strain (22). Rac $2^{-/-}$mice were backcrossed for 12 generations into a C57BL/6J strain as previously described (23). The $p 85 \alpha^{+/-}$mice were obtained in a C57BL/6J.129 background from Lewis Cantley at Harvard University (Boston, Massachusetts, USA) and backcrossed for eight generations into a C57BL/6J strain (24). $W^{41} / W^{41}$ mice ( $W$ indicates the white-spotted locus) were obtained in a C57BL/6J background from The Jackson Laboratory (Bar Harbor, Maine, USA). These studies were conducted with a protocol approved by the Indiana University Laboratory Animal Research Center. The Nf1, p85 $\alpha$, and Rac2 alleles were genotyped by PCR, as previously described $(13,24)$. The $W^{41}$ genotyping was inferred from the characteristic mottled, white coat color in the $W^{41} / W^{41}$ mice and a white abdominal spot in the $W^{41+-}$ mice (12). Multiple F0 founders were used to generate the four F2 Nf1 and Rac2 genotypes used in the experiments as follows: F0: $\mathrm{Nf1}^{+/-} ; \mathrm{RaC2}^{+/+} \times \mathrm{Nf1}^{+/+} ; \mathrm{RaC2}^{-/-}$. F1: $\mathrm{Nf1}^{++-} ; \mathrm{Rac2}^{+/-} \times \mathrm{Nf1}^{+++} ; \mathrm{RaC2}^{+/-}$. $\mathrm{F} 2: \mathrm{Nf1}^{1^{+/}} ; \mathrm{Rac2}^{-/-} \times \mathrm{Nf1}^{+++}$; $\mathrm{Rac2}^{-/-}, \mathrm{Nf1}^{+/-} ; \mathrm{Rac}^{+/+} \times \mathrm{Nf1}^{+/+} ; \mathrm{Rac2}^{+/+}$. Multiple F0 founders were used to generate mast cells from embryonic day 13.5 fetal liver from the four F2 Nf1 and $p 85 \alpha$ genotypes as follows: F0: $\mathrm{Nf1}^{+/-} ; \mathrm{p} 85 \alpha^{+/+} \times N \mathrm{N1}^{+/+} ; \mathrm{p} 85 \mathrm{\alpha}^{+/-}$. F1: $\mathrm{ff}^{1^{+/-}} ; \mathrm{p} 85 \alpha^{+/-} \times \mathrm{Nf1}^{+/+} ; p 85 \alpha^{+/-}$. F2: $\mathrm{Nf1}^{+/-} ; p 85 \alpha^{-/-} \times$

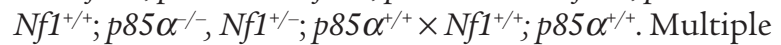
F0 founders were used to generate the four F2 Nf1 and $W^{41}$ genotypes as follows: F0: $N f 1^{+/-} ; W^{41^{+/+}} \times N f 1^{+/+}$; $W^{41} / W^{41}$. F1: $\mathrm{Nf1}^{+/-} ; \mathrm{W}^{41^{++}-} \times \mathrm{Nf1}^{+/+} ; \mathrm{W}^{41^{4+-}}$. F2: $\mathrm{Nf1}^{+/-}$; $W^{41} / W^{41} \times N f 1^{+++} ; W^{41} / W^{41}, N f 1^{+/-} ; W^{41+++} \times N f 1^{+++} ; W^{41+++}$. Bone marrow mast cell and fetal liver mast cell cultures. To generate the four $\mathrm{F}_{2} \mathrm{Nf1}$ and Rac2 experimental genotypes and the four $\mathrm{F}_{2} N f 1$ and $W^{41}$ experimental genotypes, five bone marrow-derived mast cell (BMMC) lines from each genotype were generated from 8-week-old mice. To generate the four $\mathrm{F}_{2} \mathrm{Nf1}$ and $p 85 \alpha$ experimental genotypes, embryonic day 13.5 fetal liver-derived mast cells (FLMCs) were generated exactly as previously described (13). BMMCs and FLMCs were cultured as previously described with minor modifications, and the homogeneity of BMMCs and FLMCs was determined by Giemsa staining (12). Aliquots of cells were also stained with Alcian blue and Safranin to confirm that they were mast cells (25). Furthermore, FACS analysis (Becton Dickinson Immunocytometry Systems, San Jose, California, USA) revealed similar forward and side light-scatter characteristics and the same percentage of ${\mathrm{c}-\mathrm{kit}^{+}}^{+}$ expression in BMMCs and FLMCs for all murine experimental genotypes (data not shown).

Schwann cell culture and generation of conditional Schwann cell media. Murine Schwann cells were isolated from WT $\mathrm{Nf1}^{+/-}$and $\mathrm{Nf1}^{-{ }^{--}}$mutant mouse embryo dorsal root ganglia (DRG) at embryonic day 13.5 as described previously (26). DRGs of the embryos were enzymatically dissociated, and cells from single embryos were plated in a single well of a 12-well tissue culture plate in DMEM (Invitrogen Corp., Grand Island, New York, USA) containing 10\% FBS (HyClone Laboratories, Logan, Utah, USA) supplemented with $250 \mathrm{ng} / \mathrm{ml} \mathrm{NGF}$ 


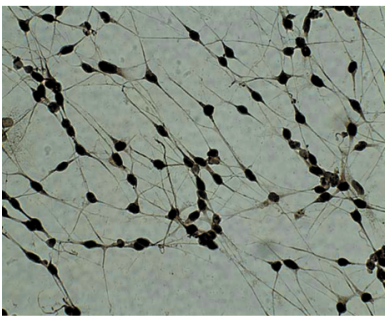

WT

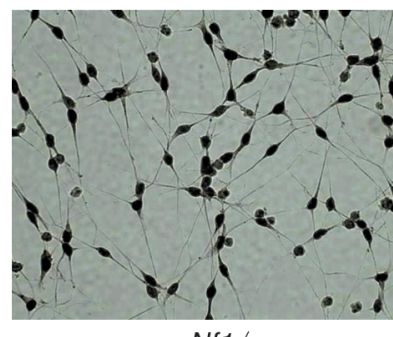

$\mathrm{Nf1}^{-/-}$
Figure 1

Isolation of purified populations of Schwann cells from day 13.5

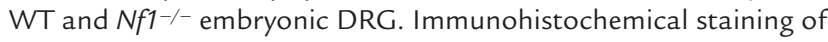
S-100 Schwann cells.

(Harlan Bioproducts for Science Inc., Indianapolis, Indiana, USA). The medium was changed to serum-free defined N2 medium (Invitrogen Corp.) containing 250 $\mathrm{ng} / \mathrm{ml} \mathrm{NGF}$ and penicillin/streptomycin $(1 \mathrm{mM} / \mathrm{ml})$ (BioWhittaker Inc., Walkersville, Maryland, USA) on the next day. After 5-6 days, Schwann cells and neurons were separated from fibroblasts by lifting up the Schwann cell-neuron layers from the dish, leaving the fibroblasts behind. Cells from the same genotype were pooled, and Schwann cells were enzymatically dissociated from the neurons in $0.01 \%$ collagenase (SigmaAldrich, St. Louis, Missouri, USA). Cells were centrifuged, resuspended in DMEM with 10\% FBS, and plated on poly-L-lysine-coated 100-mm diameter cell culture plates (Becton Dickinson and Co., Franklin Lakes, New Jersey, USA) at a density of approximately $10^{6}$ cells/plate. These cells were considered passage 0 . Cells were changed on the next day to Schwann cell growth medium containing $10 \mathrm{ng} / \mathrm{ml}$ recombinant human glial growth factor 2 (rhGGF2) (Heregulin; Sigma-Aldrich), $1 \mathrm{mM} / \mathrm{ml}$ penicillin/streptomycin, with $2 \mathrm{mM}$ forskolin (EMD Biosciences Inc., San Diego, California, USA) added to suppress fibroblast growth. After 1 week, cells were trypsinized and replated at $10^{6}$ cells/plate (passage 1). Cultures were stained with an $\mathrm{Ab}$ directed against S-100 (Sigma-Aldrich), an acidic, calcium-binding protein present in Schwann cells and not fibroblasts, to verify the purity of Schwann cell populations (Figure 1). In all experiments, cells prepared between passages 1 and 3 were used. Cells were kept in serum-free N2 medium supplemented with rhGGF2 and forskolin from passage 0 throughout the culture period. Conditioned media (CM) was harvested as previously described from Schwann cell cultures on passage 2 after 24 hours of culture in serum-free DMEM (26). WT, $\mathrm{Nf1}^{+/}$, and $\mathrm{Nf1}^{-/-}$Schwann cell viability was greater than $95 \%$ by trypan blue (Sigma-Aldrich) exclusion after culture in serum-free DMEM (data not shown). The doubling time for $\mathrm{Nf1}^{+/+}, \mathrm{Nf1}^{+/}$, and $\mathrm{Nf1}^{-/-}$Schwann cells was approximately 92,74 , and 44 hours, respectively.

Quantification of KitL in conditional Schwann cell media. Quantitative concentration of murine KitL in Schwann cell-conditioned media was determined by ELISA using Quantikine M to measure KitL, according to the manufacturer's protocol (R\&D Systems Inc., Minneapolis, Minnesota, USA). Protein arrays on Schwann cell-conditioned media were performed with a protein array assay kit exactly according to the manufacturer's protocol (mouse cytokine array kit; Raybiotech Inc., Norcross, Georgia, USA).

$A b$ 's and fluorescence cytometric analysis. Phycoerythrinconjugated (PE-conjugated) mAb's were directed against c-kit and $\alpha_{5} \beta_{1}$. FITC-conjugated Ab's were directed against $\alpha_{4} \beta_{1}$. All the PE and FITC-conjugated $\mathrm{mAb}$ 's, including isotype control Ab's, were purchased from PharMingen (San Diego, California, USA). Mast cells $\left(10^{6}\right)$ were incubated at $4^{\circ} \mathrm{C}$ for 30 minutes with 1 $\mu \mathrm{g}$ of the primary mAb. Cells were washed three times with PBS containing 0.1\% BSA (Sigma-Aldrich) and analyzed by FACS.

Generation of recombinant retroviral plasmids. Previously developed recombinant retrovirus constructs were used in these studies (27). The internal sequences of these constructs are under the transcriptional control of the myeloproliferative sarcoma retrovirus promoter. Constructs also contain a puromycin resistance gene, pac, which is under the transcriptional control of the phosphoglycerate kinase promoter. Three viruses were used in these experiments: (a) a virus expressing the fulllength NF1 GTPase-activating related domain (NF1 GRD) and pac (MSCV-NF1 GRD-pac); (b) a virus expressing a GAP-inactive mutant of the NF1 GRD that harbors a known human mutation in the arginine finger loop (R1276P) (28) and pac (MSCV-1276P NF1 GRD-pac), and (c) a virus expressing the selectable marker gene alone (MSCV-pac) (27).

Retroviral infection of FLMCs. Fetal liver cells were transduced as previously described (27). Briefly, embryonic day 13.5 fetal liver cells recovered from genotyped livers were prestimulated for 48 hours in liquid cultures of RPMI containing 20\% FBS supplemented with KitL $(100 \mathrm{ng} / \mathrm{ml})$ (Peprotech Inc., Rocky Hill, New Jersey, USA) and IL-6 (200 U/ml) (Peprotech Inc.). Cells were transduced on mitomycin C-treated E86 producer cells in the presence of KitL, IL- 6 , and Polybrene $(5 \mu \mathrm{g} / \mathrm{ml})$ for 48 hours. Transduced cells were then cultured under conditions to promote mast cell growth as described previously and as above (27).

Integrin-directed (haptotaxis) migration assays. Integrindirected migration (haptotaxis) assays were performed as previously described (29). Briefly, Falcon cell culture inserts containing polyethylene terepthalate tratetched membranes (Fisher Scientific Co., Pittsburgh, Pennsylvania, USA) were coated on the underside with $20 \mu \mathrm{g} / \mathrm{ml}$ fibronectin (FN) peptides (Takara Bio Inc., Shiga, Japan) for 2 hours at $37^{\circ} \mathrm{C}$, rinsed with PBS, and blocked with $2 \%$ BSA for 30 minutes at room temperature. The transwells were then placed into the lower chamber containing $500 \mu \mathrm{l}$ of RPMI medium alone or in combination with either KitL, WT-conditioned Schwann cell media, $\mathrm{Nf1}^{+/-}$Schwann cell-conditioned media, or $\mathrm{Nf1}^{-/-}$-conditioned Schwann cell media. Mast 
a

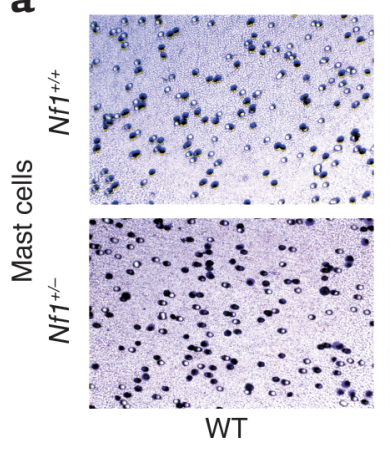

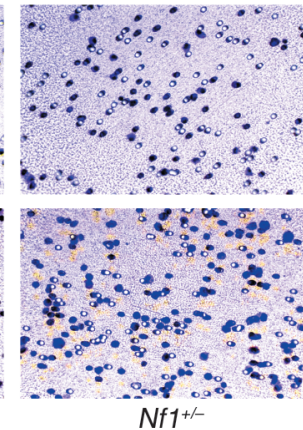

Schwann cell media

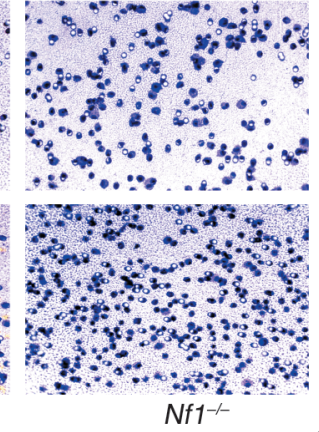

b

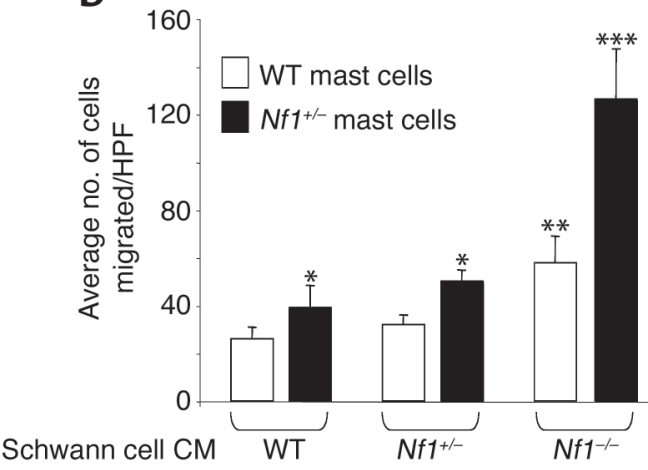

Figure 2

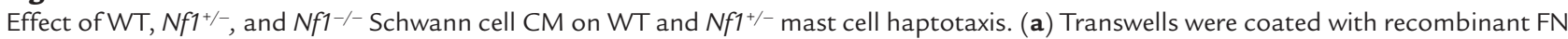
and mast cell migration assays were performed in response to WT, $\mathrm{Nf1}^{+/-}$, and $\mathrm{Nf1}^{-/-}$Schwann cell CM. The number of WT and $\mathrm{Nf1^{+/- }}$ mast cells that had migrated to the bottom surface of the FN-coated membrane in response to Schwann cell CM were counted after staining the

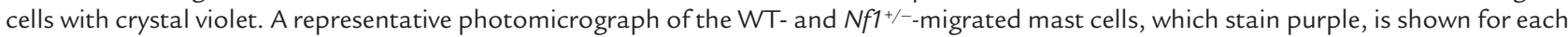
experimental condition. (b) The average numbers of WT and $\mathrm{Nf}^{+/-}$mast cells per ten high-power fields, which migrated in response to either $10^{5} \mathrm{WT}, \mathrm{Nf1^{+/- }}$, or $\mathrm{Nf1^{-/- }}$ Schwann cell CM are shown. Data represent the mean number of migrated cells per ten high-power fields $\pm \mathrm{SEM}$ of four independent experiments. ${ }^{*} P<0.05$ for $N f 1^{+/-}$versus WT mast cells in response to either WT Schwann cell $\mathrm{CM}$ or $N f 1^{+/-}$Schwann cell CM. ${ }^{* *} P<0.05$ for WT mast cells in response to both WT and $N f 1^{+/-}$Schwann cell CM versus $N f 1^{-/-}$Schwann cell CM; ${ }^{* * *} P<0.01$ for $\mathrm{Nf1^{+/- }}$ mast cells in response to both WT and $\mathrm{Nf1}^{+/-}$versus $\mathrm{Nf1}^{-/-}$Schwann cell CM by the Student's paired $t$ test. HPF, high-power field.

cells were resuspended at $1 \times 10^{5}$ to $2 \times 10^{5}$ cells in 100 $\mu \mathrm{l}$ of RPMI medium added to the top of each chamber and allowed to migrate toward the underside of the top chamber. Following 3 hours of incubation at $37^{\circ} \mathrm{C}$ in a $5 \% \mathrm{CO}_{2}$ incubator, nonmigratory cells on the upper membrane surface were removed with a cotton swab, and migrated cells attached to the bottom surface of the membrane were stained with $0.1 \%$ crystal violet in $0.1 \mathrm{M}$ borate, $\mathrm{pH}$ 9.0, $2 \%$ ethanol for 20 minutes at room temperature as previously described (29). The average number of migrated cells per higher-power field was counted with an inverted microscope using $\times 20$ objective lens. As a control, cell migration on BSA was also determined and was less than $0.001 \%$ of the total cell population (data not shown).

Motility assay. Mast cell motility was directly observed by time-lapse imaging of cells exposed to a gradient of $10 \mathrm{ng} / \mathrm{ml} \mathrm{KitL}$ in a Dunn chemotaxis chamber (Weber Scientific International Ltd., Surrey, United Kingdom). Cells $\left(2 \times 10^{4}\right.$ to $5 \times 10^{4}$ in $10 \mu \mathrm{l}$ RPMI) were applied to FN fragment H-296-covered (Takara Bio Inc.) glass coverslips and allowed to adhere for 10 minutes at $37^{\circ} \mathrm{C}$. The coverslips were mounted on the Dunn chamber, the inner well of which was filled with RPMI and the outer well with RPMI and KitL. The chamber was sealed and mounted on the stage of a Nikon Diaphot 300 inverted microscope equipped with differential interference contrast optics (Olympus America Inc., Melville, New York, USA). Chamber temperature was maintained at $37^{\circ} \mathrm{C}$ using a stage heater (Instec Inc., Boulder, Colorado, USA). The chamber was allowed to equilibrate for 20 minutes to allow a stable gradient to form. Images were recorded digitally at 15second intervals using a $\times 40$ long working distance objective and a Spot RT-cooled charged coupled device camera and analyzed using Metamorph software (Universal Imaging Corp., West Chester, Pennsylvania, USA). The centroid coordinates of cells at each time point were determined on calibrated images and used to calculate the speed and direction of migration.

Filamentous actin quantitation. Filamentous actin (F-actin) quantitation was performed as previously described (30). Briefly, fluorescence cytometry was used to quantitate the amount of F-actin per mast cell. Mast cells $\left(10^{6}\right)$ were resuspended in $1 \mathrm{ml}$ of HBSS (SigmaAldrich) in polypropylene tubes (Fisher Scientific Co., Hanover Park, Illinois, USA) and warmed at $37^{\circ} \mathrm{C}$ for 3 minutes prior to addition of KitL or carrier. Cells were fixed after the specified time by addition of $10 \mathrm{vol}$ of PBS containing $4.6 \%$ formaldehyde and $0.1 \%$ BSA. Fixed cells were treated with $0.01 \%$ Triton X-100 (Sigma-Aldrich) in PBS for 5 minutes at $22^{\circ} \mathrm{C}$, washed, and then incubated with $160 \mathrm{nM}$ FITC-phalloidin (Sigma-Aldrich) for 20 minutes at $22^{\circ} \mathrm{C}$ prior to FACS analysis by fluorescence cytometry. A minimum of 10,000 mast cell events was recorded routinely, and the results are reported as the mean channel fluorescence. Assays were performed in triplicate.

\section{Results}

$N 1^{-/-}$Schwann cell-conditioned media is a potent stimulus for $\mathrm{Nf1}^{+/-}$mast cell migration. The mechanism of $\mathrm{Nf1}^{+/-}$ mast cell recruitment to neurofibromas is not known. Thus, we tested whether Nf1-deficient Schwann cells secrete soluble factors to stimulate mast cell migration. We initially isolated DRG from day $13.5 \mathrm{WT}, \mathrm{Nf1}^{+/}$, and $\mathrm{Nf1}^{-/-}$embryos to establish primary murine Schwann cell cultures. To ensure the purity of these cultures, cells were stained with an Ab directed against S-100, an acidic, calcium-binding protein present in 


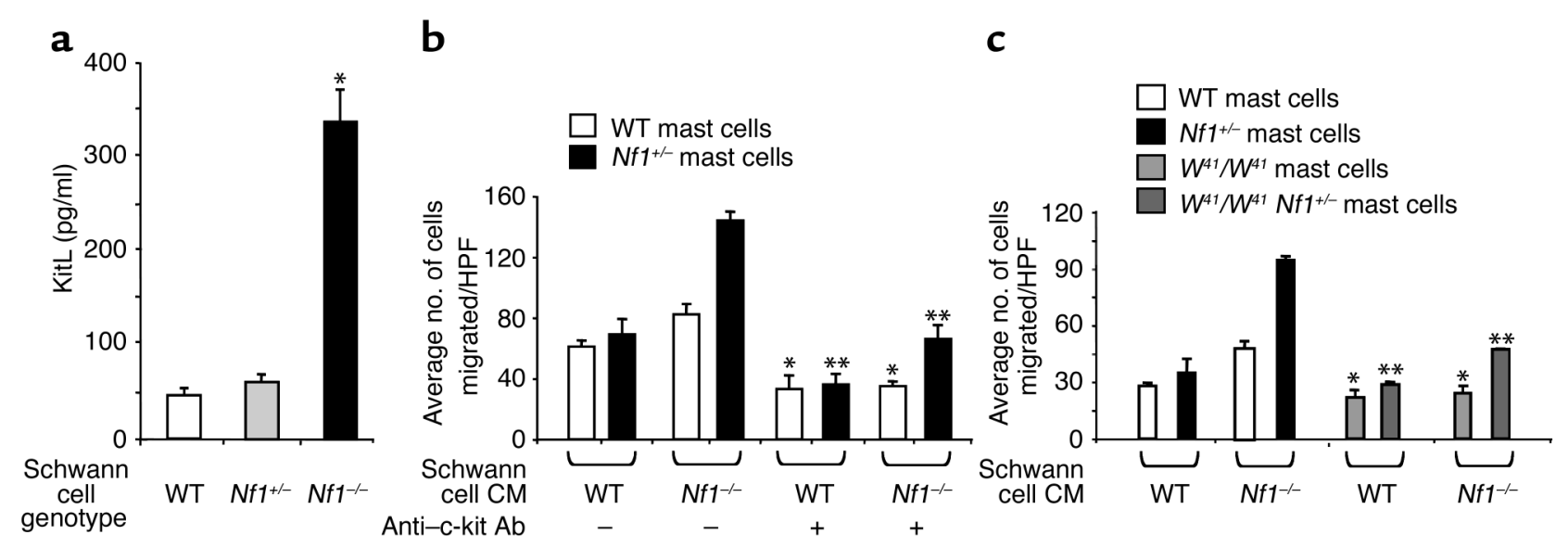

Figure 3

Quantification of the concentration of KitL in Schwann cell CM and the effect of pharmacologic or genetic inhibition of c-kit activity on mast cell migration to Schwann cell CM. (a) Concentration of murine KitL in WT, $\mathrm{Nf1}^{+/-}$, and $\mathrm{Nf1}^{-/-}$Schwann cell CM was determined by ELISA. Results represent the mean \pm SEM of five independent collections from five independent Schwann cell cultures. ${ }^{*} P<0.05$ for $N f 1^{-/-}$versus WT or $N f 1^{-/-}$versus $N f 1^{+/-}$by the Student's paired $t$ test. (b) WT and $N f 1^{+/-}$mast cells $\left(2 \times 10^{5}\right)$ were preincubated with a neutralizing Ab to the c-kit RTK, and haptotaxis assays were performed to either WT or $\mathrm{Nf1}^{-/-}$Schwann cell CM. Results represent the mean \pm SEM of five independent experiments. ${ }^{*} P<0.05$ for WT mast cell migration in response to WT or $N f 1^{-/-}$Schwann cell CM in the presence or absence of the c-kit-neutralizing Ab. ${ }^{*} P<0.05$ for $N f 1^{+/-}$mast cell migration in response to WT or $\mathrm{Nf1}^{-{ }^{-}-}$Schwann cell $\mathrm{CM}$ in the presence or absence of the c-kit-neutralizing Ab by the Student's paired $t$ test. (c) Haptotaxis of mast cells of the four $N f 1$ and $W$ genotypes in response to either $2 \times 10^{5} \mathrm{WT}$ or $\mathrm{Nf1}^{-/-}$Schwann cell CM. Results represent the mean \pm SEM of five independent experiments. ${ }^{*} P<0.05$ for $W^{41} / W^{41}$ versus WT mast cell migration in response to either WT or $N f 1^{-/-}$Schwann cell CM. ${ }^{*} P<0.05$ for $N f 1^{+/-} ; W^{41} / W^{41}$ versus $N f 1^{+/-}$mast cell migration in response to either WT or $N f 1^{-/-}$Schwann cell CM by the Student's paired $t$ test.

Schwann cells, and performed immunohistochemistry. Greater than $98-100 \%$ of the cells in WT, $N f 1^{+-}$, and $\mathrm{Nf1}^{-/-}$cultures were S-100 positive as analyzed by immunohistochemistry (Figure 1). To further test the purity of our cultures, we made single-cell suspensions and stained the cells with a fluorescence-conjugated $\mathrm{Ab}$ directed against S-100 and performed fluorescence cytometry; $98-100 \%$ of the cells in each experimental group expressed S-100 (data not shown).

After obtaining primary WT, $\mathrm{Nf1}^{+/-}$, and $\mathrm{Nf1^{-/ }}$ Schwann cells, we collected CM from each genotype. To test whether WT, $\mathrm{Nf1}^{+/}$, or $\mathrm{Nf1}^{-/-} \mathrm{CM}$ would stimulate either WT or $\mathrm{Nf1}^{+-}$mast cell migration, we coated transwells with recombinant FN and performed migration assays in response to WT, $\mathrm{Nf1}^{+/-}$, and $\mathrm{Nf1}^{-/-} \mathrm{CM}$. After 3 hours of incubation in the transwells, the number of $\mathrm{Nf1}^{+/-}$and WT mast cells that had migrated to the bottom surface of the FN-coated membrane were counted after staining the cells with crystal violet. WT and $\mathrm{Nf1}^{+/-}$ mast cells migrated in response to CM from each Schwann cell genotype (Figure 2, a and b). While the migration of both mast cell genotypes was augmented in response to $\mathrm{Nf1}^{-/-}$Schwann cell CM, the tumorigenic cell in neurofibromas (8), the absolute number of $\mathrm{Nf}^{+/-}$mast cells migrating to $\mathrm{Nf1}^{-1-}$ Schwann cell-conditioned media is significantly higher compared with WT mast cells (Figure 2b). These data demonstrate that: (a) Schwann cells secrete soluble factor(s) that stimulate mast cell migration; (b) CM from $\mathrm{Nf1}^{-/-}$Schwann cells has more potent effects in this assay than WT or $\mathrm{Nf1}^{+/-} \mathrm{CM}$; and (c) $\mathrm{Nf1}^{+/-}$ mast cells are specifically more responsive to $\mathrm{Nf1}^{-/-} \mathrm{CM}$.
Identification of KitL in $\mathrm{Nf1}^{-/-}$Schwann cell-conditioned media as a potent stimulus for $\mathrm{Nf}^{+/-}$mast cell migration. We performed protein and ELISA assays on WT and $\mathrm{Nf1}^{-{ }^{-}}$ CM to identify soluble mast cell chemotactic factor(s). In addition, we performed real-time PCR on mRNA harvested from WT or $\mathrm{Nf1}^{-1-}$ Schwann cells. These studies revealed several soluble chemokines and growth factors previously linked to mast cell migration. Specifically, VEGF, monocyte chemotactic factor 1 (MCP-1), RANTES, and KitL were detected in both WT and $\mathrm{Nf1}^{-/-}$ Schwann cell CM, and each soluble protein was found in greater concentrations in $\mathrm{Nf1}^{-/-} \mathrm{CM}$ (unpublished results). We next tested whether various concentrations of recombinant VEGF, MCP-1, or RANTES, would stimulate the migration of either WT or $\mathrm{Nf1}^{++}$mast cells by performing migration assays on $\mathrm{FN}$-coated transwells. None of these soluble proteins alone or in combination stimulated either WT or $\mathrm{Nf1}^{+/-}$mast cell migration over a wide range of concentrations, though they did modestly enhance migration in the presence of recombinant $\operatorname{KitL}(n=3$, and data not shown).

Given this observation and the fact that KitL is known to be a potent stimulus for mast cell migration both in vitro and in vivo (13), we tested whether KitL was a growth factor in WT, $\mathrm{Nf1}^{+/-}$, and $\mathrm{Nf1}^{-{ }^{--}}$Schwann cell $\mathrm{CM}$, which promotes mast cell migration. In addition, we had previously observed that $\mathrm{Nf1}^{+/-}$mast cells had increased proliferation and survival in response to KitL $(12,13)$. We determined the concentration of KitL in WT, $\mathrm{Nf1}^{+-}$, and $\mathrm{Nf1}^{-/-}$Schwann cell CM by ELISA. While KitL was detected in CM from each genotype, the 
a

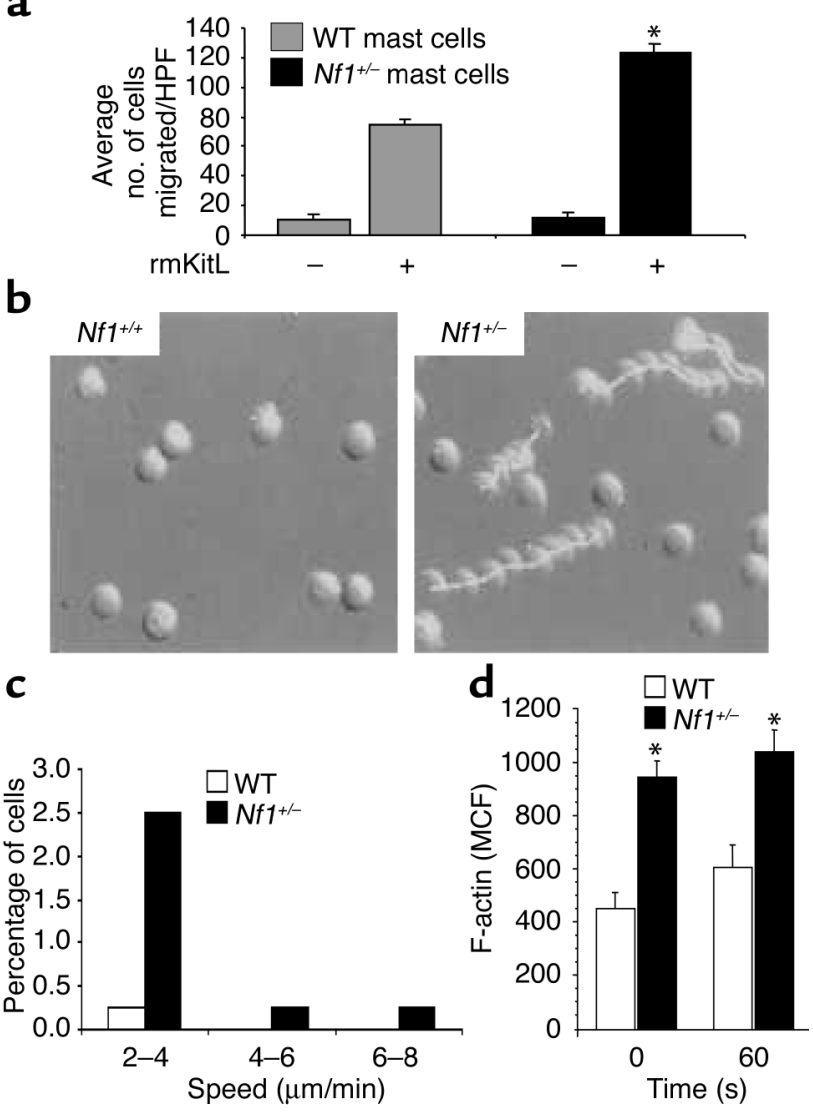

concentration of KitL was approximately sixfold higher in $\mathrm{Nf1}^{-/-} \mathrm{CM}$ compared with WT controls (Figure 3a). Interestingly, $\mathrm{CM}$ from $\mathrm{Nf1}^{+/-}$Schwann cells contained similar concentrations of KitL compared with WT CM. We next tested whether pretreatment of WT and $\mathrm{Nf}^{++}$ mast cells with a blocking $\mathrm{Ab}$ to c-kit would inhibit mast cell migration to either WT or $\mathrm{Nf1}^{---}$Schwann cell $\mathrm{CM}$ in a migration assay. Preincubating WT and $\mathrm{Nf1}^{+/}$ mast cells with an anti-c-kit Ab significantly inhibited the migration of both mast cell genotypes to either WT or $\mathrm{Nf1}^{-/-} \mathrm{CM}$ (Figure 3b). Importantly, preincubation of $\mathrm{Nf1}^{+/-}$mast cells with an anti-c-kit Ab reduced their migration to WT levels in response to $\mathrm{Nf1}^{-1-}$ Schwann cell $\mathrm{CM}$ (Figure $3 \mathrm{~b}$ ). These data suggest that the increased migration of $\mathrm{Nf1}^{+/-}$mast cells to $\mathrm{Nf1}^{-/-}$Schwann cell CM is linked, in part, to increased activation of the KitL/ c-kit-signaling pathway.

The $W$ locus encodes the c-kit receptor tyrosine kinase (RTK). We exploited the $\mathrm{W}^{41}$ strain, which carries a point mutation that reduces RTK activity approximately $85 \%$ to test the role of c-kit signaling in mast cell migration in response to Schwann cell CM. $\mathrm{W}^{41} / \mathrm{W}^{41}$ mice and $\mathrm{Nf1}^{+/}$ mice were intercrossed to generate mast cells lines from the four $\mathrm{F}_{2}$ progeny. We reasoned that $\mathrm{W}^{41} / \mathrm{W}^{41} \mathrm{Nf1}^{+/}$ mast cells would have a migration pattern similar to WT cells in response to the $\mathrm{Nf1}^{--}$-Schwann cell CM if KitL is the primary mast cell chemotactic factor responsible for the increased migration of $\mathrm{Nfl}^{+/-}$mast cells. In multiple independent migration assays, both $\mathrm{W}^{41} / \mathrm{W}^{41}$ and $\mathrm{Nf1}^{+/-}$;

\section{Figure 4}

Effect of heterozygosity of Nf1 on mast cell haptotaxis and F-actin content in response to rmKitL. (a) Haptotaxis of WT and $\mathrm{Nf1}^{+/-}$mast cells in response to $10 \mathrm{ng} / \mathrm{ml} \mathrm{rmKitL}$. Results represent the mean \pm SEM of five independent experiments. ${ }^{*} P<0.05$ for $N f 1^{+/-}$versus WT by the Student's paired $t$ test. (b) Sequential exposures of $\mathrm{Nf}^{+/-}$and WT mast cells taken at 2.5-minute intervals during exposure to a 10 $\mathrm{ng} / \mathrm{ml}$ KitL gradient (from left to right) for 1 hour. Mast cells were allowed to adhere to $\mathrm{FN}$-coated glass coverslips for 15 minutes before being loaded into the chemotactic gradient of a Zigmond chamber. $\mathrm{Nf}^{+/}$mast cells demonstrated greatly enhanced movement to the rmKitL gradient compared with WT cells. (c) Percentage of $\mathrm{N} 1^{+/-}$or WT cells moving at various speeds during videomicroscopy. The average speed of directed movement was calculated from data collected from the second 30-minute interval of videomicroscopy from WT and $\mathrm{Nf1^{+/ }}$ samples ( $n>100$ cells analyzed per genotype). Histogram depicts the results from one representative experiment. Two other experiments showed similar results. (d) F-actin content in BMMCs. Mast cells were stimulated with $10 \mathrm{ng} / \mathrm{ml} \mathrm{rmKitL}$ and fixed, at the time points indicated, by addition of formaldehyde. WT and $\mathrm{Nf}^{+/-}$cells were examined in triplicate. Results are expressed as mean channel fluorescence (MCF) and represent the mean of four independent experiments per genotype. ${ }^{*} P<0.001$ for all comparisons between genotypes using a Student's paired $t$ test.

$W^{41} / W^{41}$ mast cells had decreased migration in response to WT and $\mathrm{Nf1}^{-/-} \mathrm{CM}$ compared with WT and $\mathrm{Nf1}^{+/-}$ mast cell controls (Figure 3c). Importantly, $\mathrm{Nf1}^{+/-}$; $W^{41} / W^{41}$ mast cell migration was reduced to WT levels in response to $\mathrm{Nf1}^{-1-}$ Schwann cell CM (Figure 3c). Thus, these experiments identify KitL as a soluble growth factor in $\mathrm{Nf1}^{-/-}$Schwann cell CM that preferentially enhances the migration of $\mathrm{Nf1}^{+/-}$mast cells.

Haploinsufficiency of $N f 1$ increases mast cell migration and F-actin content in response to recombinant murine KitL. We have previously shown that $\mathrm{Nf1}^{+-}$mast cells have increased proliferation and survival in response to KitL

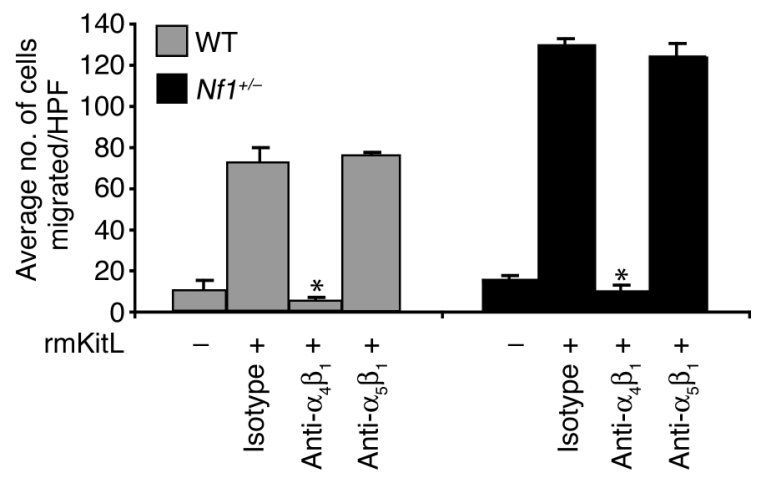

Figure 5

Effect of inhibition of adherence to the $\alpha_{4} \beta_{1}$ or $\alpha_{5} \beta_{1}$ integrins on WT and $\mathrm{Nf1}^{+-}$- mast cell haptotaxis. WT and $\mathrm{Nf1}^{+/-}$mast cells were preincubated with a neutralizing Ab to the $\alpha_{4} \beta_{1}$ or $\alpha_{5} \beta_{1}$ integrins, or an isotype control $A b$, and haptotaxis assays were performed to rmKitL. Results represent the mean \pm SEM of five independent experiments following a 3-hour stimulation to KitL. ${ }^{*} P<0.05$ for WT or $\mathrm{Nf1}^{+/-}$ mast cell migration in response to recombinant KitL in presence or absence of the $\alpha_{4} \beta_{1}$-neutralizing $A b$ or the isotype $A b$ control using a Student's paired $t$ test. 


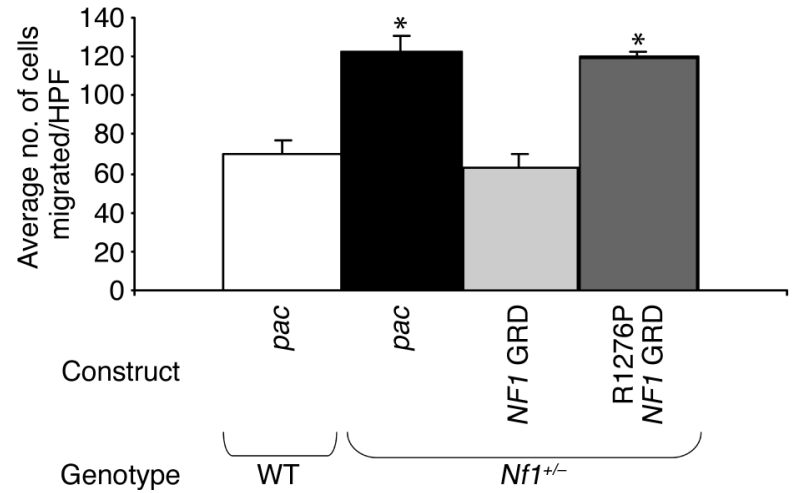

Figure 6

Haptotaxis of $\mathrm{Nf1}^{+/-}$mast cells expressing NF1 GRD or R1276P mutant NF1 GRD. Nf1 ${ }^{+/-}$mast cells were transduced with the control retrovirus (pac), NF1 GRD virus, or R1276P NF1 GRD virus, and haptotaxis assays were performed in response to rmKitL. Results represent the mean \pm SEM of three independent experiments. ${ }^{*} P<0.05$ for comparison of $N f 1^{+/-}$pac and $N f 1^{+/-}$R1276P NF1 GRD to WT pac using a Student's paired $t$ test.

and have identified distinct Ras effector pathways responsible for these phenotypes (13). Given that $N f 1^{+/-}$ mast cells have increased migration to $\mathrm{Nf1}^{-{ }^{--}}$Schwann cell CM, which is mediated in part via signaling through the KitL/c-kit pathway, we wished to identify the biochemical mechanisms responsible for this $\mathrm{Nf1}^{+/-}$ mast cell phenotype. To confirm that $\mathrm{Nf1}^{+/-}$mast cells would also demonstrate increased migration in response to recombinant murine KitL (rmKitL), we coated transwells with recombinant $\mathrm{FN}$ and compared the migration of WT and $\mathrm{Nf1}^{+/-}$mast cells to rmKitL. Consistent with increased migration to Schwann cell $\mathrm{CM}, \mathrm{Nf1}^{+/-}$mast cells had a twofold increase in migration in response to rmKitL compared with WT controls (Figure 4a). We next compared the migration of $\mathrm{Nf1}^{+/}$ and WT mast cells on FN-coated surfaces in response to rmKitL using single-cell video microscopy. Similar to our results using FN-coated transwells, a greater percentage of $\mathrm{Nf1}^{+/-}$mast cells moved at greater speeds compared with WT controls (Figure 4, b and c).

Polymerization of the actin cytoskeleton drives the initial extension of the plasma membrane at the cell front to form small adhesions, which promotes rapid cell migration (31). Given the increased migration rate of $\mathrm{Nf1}^{+/-}$mast cells, we compared F-actin content in $\mathrm{Nf1} 1^{+/-}$and WT mast cells following stimulation with rmKitL. Following activation with rmKitL, both mast cell genotypes were stained with phalloidin to quantitate levels of F-actin by both fluorescence cytometry and microscopy. In both assays, $\mathrm{Nf1}^{+/-}$mast cells had increased F-actin content compared with WT cells after 1 minute of stimulation with rmKitL (Figure 4d). Surprisingly, $\mathrm{Nf1}^{+/-}$mast cells had greater F-actin content at baseline compared with F-actin content obtained in WT cells stimulated with rmKitL (Figure 4d). Importantly, in multiple independent experiments $(n=6)$, the adhesion of $\mathrm{Nf}^{+/-}$mast cells to $\mathrm{FN}$ at baseline and in response to rmKitL over varying amounts of time was not different compared with WT cells (data not shown). Thus, differences in migration between the two experimental genotypes cannot be explained by differences in adhesion to FN.

Increased migration of $\mathrm{Nf}^{+1 /-}$ mast cells to rmKitL is mediated by signaling through the $\alpha_{4} \beta_{1}$ integrin. We have recently shown that activation of c-kit by rmKitL cooperates with the $\alpha_{4} \beta_{1}$ integrin to direct the migration of WT mast cells on FN (29). Furthermore, previous studies, including analysis of mice deficient in the expression of the $\alpha_{4} \beta_{1}$ integrin, suggest that $\alpha_{4} \beta_{1}$ has an essential role in normal hematopoietic cell development and recruitment of immune cells to local sites of inflammation $(32,33)$. To test whether the increased migration of $\mathrm{NfI}^{+/-}$mast cells to rmKitL on $\mathrm{FN}$ is mediated specifically by $\alpha_{4} \beta_{1}$, we pretreated $N \mathrm{N1}^{+/-}$and WT mast cells with blocking $A b$ 's against $\alpha_{4} \beta_{1}$ and $\alpha_{5} \beta_{1}$, which are the two integrins expressed on recombinant FN. Compared with the isotype control, anti- $\alpha_{4} \mathrm{Ab}$ treatment of both WT and $\mathrm{Nf1}^{+/-}$cells completely inhibited the migration of both mast cell genotypes (Figure 5). Importantly, anti- $\alpha_{5} \beta_{1}$ treatment of WT and $\mathrm{Nf1}^{+/-}$ mast cells did not inhibit the migration of either mast
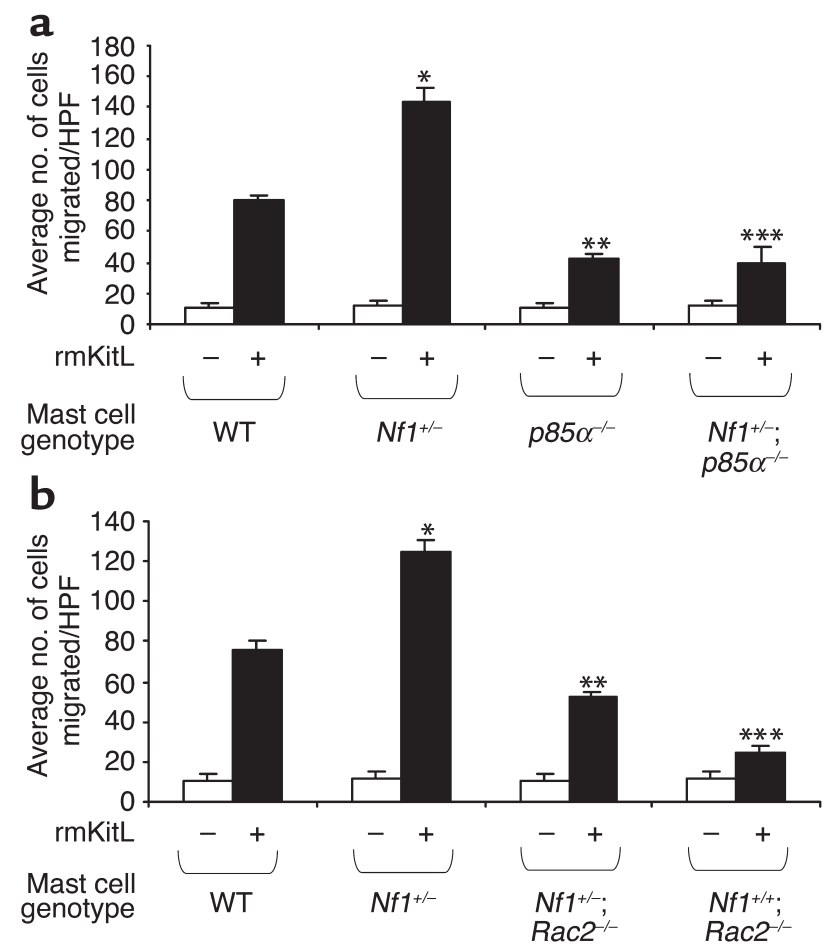

Figure 7

Effect of Rac2 or $p 85 \alpha$ deficiency on the haptotaxis of $\mathrm{Nf}^{+/-}$and WT mast cells. (a) Haptotaxis of mast cells of the four Nf1 and $p 85 \alpha$ genotypes in response to rmKitL. ${ }^{*} P<0.01$ for WT versus $\mathrm{Nf1} 1^{+/-} .{ }^{*} P<0.01$ for WT versus $p 85 \alpha^{-/-} .{ }^{* * *} P<0.01$ for $N f 1^{+/-}$ versus $N f 1^{+/-} ; p 85 \alpha^{/-}$by the Student's paired $t$ test. (b) Haptotaxis of mast cells of the four $N f 1$ and Rac2 genotypes in response to rmKitL. ${ }^{*} P<0.01$ for $\mathrm{WT}$ versus $N f 1^{+/-}$.; $N f 1^{+/+}$. ${ }^{*} P<0.01$ for $\mathrm{Nf1} 1^{+/-} ; \mathrm{Nf1^{+/+ }}$ versus $\mathrm{Nf1^{+/- }}$; Rac2 ${ }^{-/-} .{ }^{* * *} P<0.01$ for WT versus Rac $2^{-/-}$by the Student's paired $t$ test. 
cell genotype on FN in response to rmKitL (Figure 5). To ensure that differences between $\mathrm{Nf1}^{+/-}$and WT mast cell migration were not secondary to different expression of either $\alpha_{4} \beta_{1}$ or $\alpha_{5} \beta_{1}$, we compared the surface expression of these two integrins on WT and $\mathrm{Nfl}^{+/}$ mast cells. No difference in the surface expression of either $\alpha_{4} \beta_{1}$ or $\alpha_{5} \beta_{1}$ was observed between the two mast cell genotypes (data not shown). Importantly, we did not detect any differences between the adhesion of $\mathrm{Nf1}^{+/-}$or WT mast cells to either $\alpha_{4} \beta_{1}(\mathrm{H} 296)$ or $\alpha_{5} \beta_{1}$ (CH296) to account for differences in migration (data not shown). Thus, the increased migration of $\mathrm{Nf1}^{+/-}$ and WT mast cells on FN in response to rmKitL is specifically mediated by $\alpha_{4} \beta_{1}$.

Expression of the NF1 GRD in $\mathrm{Nf1}^{+/-}$mast cells restores migration to WT levels. Previous studies using nonhematopoietic cells transduced with either dominant negative or constitutively active Ras isoforms have yielded conflicting results about the role of Ras activation in regulating cellular migration (34-40). We found that $\mathrm{Nf1}^{+/-}$mast cells stimulated with rmKitL have increased Ras activity as compared with WT cells (13). While the GRD of neurofibromin binds Ras with high affinity and induces a $10^{5}$-fold increase in the rate of GTP hydrolysis (41), it is possible that actinmediated cytoskeletal functions such as migration may be altered in Nf1-deficient cells secondary to the loss of non-GRD functions of neurofibromin. To determine whether the increased migration of $\mathrm{Nf1}^{++-}$ mast cells is directly linked to increased Ras activation, we transduced $\mathrm{Nf1}^{+/-}$and WT mast cells with either a retrovirus encoding NF1 GRD (MSCV-NF1 GRD-pac) or a control retrovirus (MSCV-pac) and performed migration assays on FN-coated transwells in response to recombinant KitL. As previously shown in primary mast cells (27), we confirmed recombinant GRD peptide expression in mast cells by immunoblotting using a KT3 epitope tag incorporated into the GRD peptide (data not shown) (27). In addition, we have shown previously that immunoprecipitated GRD peptides in transduced mast cells have GAP activity by stimulating phosphate release from GTPloaded Ras (27). Interestingly, expressing the NF1 GRD in $\mathrm{Nf}^{+/-}$mast cells restored migration to normal (Figure 6). Given the specificity of the NF1 GRD in correcting the migration phenotype of $\mathrm{Nf}^{+/-}$mast cells, we further tested whether this was due to a direct effect on Ras. We used a previously generated GAP-inactive mutant of NF1 GRD that harbors a mutation in the arginine finger loop (R1276P) (28). This mutation, which was identified in a family with a typical NF1 disease, greatly reduces neurofibromin GAP activity, and we have previously shown that the R1276P mutant recombinant protein has no catalytic activity in a GAP assay in mast cells. Expressing the R1276 mutant protein in $\mathrm{Nf1}^{+/-}$mast cells had no effect on migration (Figure 6). Collectively, these data directly link hyperactivation of Ras in $\mathrm{N}^{+/-}$mast cells to increased migration on FN in response to rmKitL.
Increased migration of $\mathrm{Nf1}^{+/-}$mast cells is mediated by signaling through the class $I_{A}$ PI3K-Rac2 pathway. Given that elevated Ras activity is responsible for the increased migration of $\mathrm{Nf}^{++-}$mast cells, we next performed experiments to identify Ras effector-signaling pathways responsible for the $\mathrm{Nf}^{+/-}$migration phenotype. We have recently shown that activation of class $\mathrm{I}_{\mathrm{A}}$ PI3K and the hematopoietic-specific Rho GTPase, Rac2, is essential for $\alpha_{4}$ integrin-directed migration of WT mast cells in response to rmKitL (29). We have also identified class $\mathrm{I}_{\mathrm{A}} \mathrm{PI} 3 \mathrm{~K}$ and Rac2 as specific downstream Ras effectors that are hyperactivated in $\mathrm{Nf1}^{+/-}$mast cells in response to rmKitL stimulation (13). Given these previous observations, we used cells from compound mutant mice to test whether increased activation of the class $\mathrm{I}_{\mathrm{A}}$ PI3K-Rac2 pathway was directly linked to the $\mathrm{Nf}^{+/-}$mast cell migration phenotype.

$\mathrm{Nf1}^{+/-}$mice were intercrossed with $p 85 \alpha^{+/-}$mice to generate $\mathrm{Nf1}^{+/-} ; p 85 \alpha^{-/}$and $p 85 \alpha^{-/-}$FLMCS along with appropriate experimental controls. In previous studies, we have shown no differences in the functional responses of FLMCs compared with BMMCs (13). $\mathrm{p} 85 \alpha$ is a regulatory subunit of class $\mathrm{I}_{\mathrm{A}} \mathrm{PI} 3 \mathrm{~K}$, and other studies have shown that $p 85 \alpha^{-1-}$ mast cells have a greater that $90 \%$ reduction in class $\mathrm{I}_{A}$ PI3K activity following stimulation with rmKitL (42). After establishing FLMCs for each experimental group, migration assays were performed on FN-coated transwells. Consistent with our previous studies, the migration of $p 85 \alpha^{-/-}$mast cells was greatly diminished in response to rmKitL compared with WT mast cells (Figure 7a). The migration of $\mathrm{Nf1}^{+/-} ; \mathrm{p}^{-1} \mathrm{\alpha}^{-/}$mast cells, however, was also greatly reduced compared with both WT and $\mathrm{Nf1}^{+/-}$mast cells (Figure 7a). Thus, while Ras activates multiple downstream signaling pathways in mast cells, Ras activation of class $\mathrm{I}_{\mathrm{A}}$ PI3K is essential for the migration of $\mathrm{Nf1}^{+/-}$mast cells on $\mathrm{FN}$ in response to rmKitL.

Our previous studies show the Rac2 activity is decreased in $p 85 \alpha^{-/-}$mast cells after stimulation with rmKitL, which genetically positions Rac2 downstream of class $\mathrm{I}_{\mathrm{A}}$ PI3K in mast cells (29). Furthermore, we have previously shown that Rac2 is hyperactivated in $\mathrm{N} \mathrm{f}^{+/-}$mast cells in response to rmKitL and Ras-Rac2 activation is directly responsible for the increased proliferation of $\mathrm{Nf}^{+/-}$mast cells (13). Rac2 ${ }^{-/-}$mice have multiple mast cell defects, including impairment of actin-mediated cytoskeletal cell functions (43). Given these previous observations and the importance of Rac2 activation in mast cell migration, we intercrossed $\mathrm{Rac2}^{-/-}$and $\mathrm{Nf1}^{+/-}$mice, established mast cells from the four $\mathrm{F}_{2}$ progeny, and performed migration assays on FN-coated transwells. Consistent with previous studies, Rac2 $^{-/-}$mast cells had diminished migration on FN in response to rmKitL compared with controls (Figure 7b). $\mathrm{Nf1}^{+/-}$; $\mathrm{Rac2}^{-/-}$mast cells had a $40-50 \%$ reduction in migration compared with $\mathrm{Nf1}^{+/-}$mast cells in response to rmKitL (Figure 7b), however. Importantly, the migration of $\mathrm{Nf1}^{+--}$; $\mathrm{Rac2}^{-/-}$mast cells was similar to WT cells in multiple independent experiments $(n=6$; 
Figure $7 \mathrm{~b}$ ). Thus, these experiments provide direct genetic evidence that the increased migration of $\mathrm{Nf1}^{+/-}$ mast cells is mediated through increased activation of the specific Rac2 isoform.

\section{Discussion}

Recent genetic studies show that $\mathrm{Nf}^{-/-}$Schwann cells are necessary but not sufficient for neurofibroma formation and demonstrate that other $\mathrm{Nf1}^{+/-}$cells within neurofibromas are essential for tumor formation (8). Specifically, when Zhu and colleagues used a Krox 20 Cre promoter to induce somatic inactivation of $N f 1$ in Schwann cells only, mice did not develop neurofibromas. When these mice were backcrossed onto an $\mathrm{Nf1}^{+/-}$ background such that all non-Schwann cell lineages were haploinsufficient at $N f 1$, however, the mice uniformly developed plexiform neurofibromas. These genetic experiments provide direct evidence that haploinsufficiency of Nf1 in non-Schwann cell lineages is required for tumor formation.

Given that mast cells increase in neurofibromas (1, $6,7,14)$ and secrete proteins within tumor microenvironments to remodel ECM and to initiate neoangiogenesis $(9,10,15)$, we hypothesized that $\mathrm{Nf1}^{-/-}$ Schwann cells secrete soluble factors to activate specific signaling pathways within $\mathrm{Nf1}^{+/-}$mast cells to promote their migration to $\mathrm{Nf1}^{-/-}$Schwann cells. $\mathrm{Nf1}^{+/-}$ mast cells, in turn, may secrete soluble factors into the tumor microenvironment. A basic tenet in mast cell biology is that bone marrow-derived mast cell progenitors circulate in the peripheral blood and migrate by transmigration through endothelial cells into tissues where they undergo final maturation under the influence of local microenvironmental factors. Adhesion and integrin-directed migration (termed haptotaxis) in part regulates the accumulation of mast cells into tissues (44). While our previous studies show that $\mathrm{Nf}^{+/-}$ mast cell progenitors have increased survival and proliferation in response to recombinant $\operatorname{KitL}(12,13)$, one potential explanation for the accumulation of mast cells in neurofibromas is that haploinsufficiency of $N f 1$ alters mast cell haptotaxis toward growth factors secreted by $\mathrm{Nf1}^{-/-}$Schwann cells.

In these experiments we demonstrate that $\mathrm{Nf1}^{-/-}$ Schwann cells secrete various proteins that have been previously linked to the recruitment of inflammatory cells to tumor microenvironments. Despite the diversity of proteins secreted by $\mathrm{Nf1}^{-1-}$ Schwann cells, we provide several lines of evidence to demonstrate that KitL is a major growth factor that promotes the migration of $\mathrm{Nf}^{++-}$mast cells. These in vitro studies are intriguing given that previous analysis in human neurofibromas reveals markedly increased amounts of KitL transcripts $(6,14)$ and that transformed human Schwann cell lines secrete high concentrations of $\operatorname{KitL}(6,45)$. While other cell types, such as fibroblasts and endothelial cells may also secrete KitL, our studies clearly demonstrate that the initiating tumorigenic cell within neurofibromas secretes at least fivefold to sixfold higher concentra- tions of KitL as compared with $\mathrm{Nf1}^{+/-}$and WT Schwann cells. It is intriguing that nullizgous loss of Nf1 may result in an increased secretion of growth factors important in tumorigenesis in a range of malignancies. Recently, Donovan and colleagues demonstrated that $\mathrm{Nf1}^{-/-}$myb immortalized myeloid cells secrete high concentrations of GM-CSF (46), a growth factor previously established to be critical to the progression of tumorigenesis in juvenile myelomonocytic leukemia (47). Thus, previous studies and the current data suggest a paradigm where loss of Nf1 results in an increase in growth factor production that initiates an autocrine or paracrine loop important for the progression of tumorigenesis. The detailed mechanisms underlying this increased secretion of cytokines in Nf1 nullizygous Schwann cells is currently being investigated.

Having identified KitL as the chemotactic stimulus secreted by $\mathrm{Nf1}^{-/-}$Schwann cells, we next designed experiments to identify the biochemical mechanisms responsible for the increased migration of $\mathrm{Nf1}^{+/-}$mast cells. Recent studies show that hematopoietic cell attachment to $\alpha_{4} \beta_{1}$ and $\alpha_{5} \beta_{1}$ is critical for migration in response to KitL, and mast cells express both integrins (29). Though neurofibromas were initially described as "white tumors," they have been found to be highly vascular (48). Importantly, endothelial cells express VCAM-1, which is the receptor for $\alpha_{4} \beta_{1}$, and human and murine mast cells readily attach to endothelial cells through VCAM-1 (49). The $\alpha_{4} \beta_{1}$-VCAM- 1 interactions are especially important since mast cells are thought to migrate to areas of inflammation by attachment and transmigration through endothelial cells $(50,51)$. In our studies, we provide experimental evidence to show that heterozygous inactivation of $\mathrm{Nf1}$ promotes rapid mast cell haptotaxis specifically on $\alpha_{4} \beta_{1}$ integrins in response to KitL.

The observation that $N \mathrm{fl}^{+/-}$mast cells have increased migration on $\alpha_{4} \beta_{1}$ integrins is interesting since other studies testing the effect of increased Ras activation on cellular migration and adhesion have yielded conflicting results (34-40). Specifically, immortalized cell lines transfected with constitutively activated Ras proteins have been shown to have either increased or decreased migration. Given these previous reports, it was unclear whether the increased migration of $\mathrm{Nf}^{+/-}$mast cells was linked to increased Ras activity in response to KitL. The NF1 gene is a large, complex gene with 60 exons. The only ascribed function of the NF1 gene in mammalian cells is to function as a GAP for Ras, however, and this function is specifically mediated through the GRD of the NF1 gene (41). Furthermore, we have previously shown previously that reintroduction of the GRD with recombinant retroviruses into $\mathrm{Nf}^{-/-}$hematopoietic progenitors diminishes their proliferative responses via decreased Ras activity (27). Similar to our previous studies (52), we found that reintroduction of the GRD into $\mathrm{Nf}^{+/-}$mast cells reduces their migration on FN to WT levels in response to KitL. Similar results were also obtained when $\mathrm{Nf1}^{-/-}$Schwann cell 
$\mathrm{CM}$ was used as a stimulus (unpublished results). In addition, we also show that introduction of a GRD harboring a known patient mutation that disables Ras GTPase activity does not alter the migration of $\mathrm{Nf1}^{+/-}$mast cells. These data provide direct evidence that the $\mathrm{Nf1}^{+/-}$motility phenotype is secondary to increased Ras activity.

An important priority in studying Nf1-deficient cells is the identification of specific Ras effector pathways, which are responsible for functional defects. While we have previously shown that multiple Ras effector pathways are altered in $\mathrm{Nf1}^{+/-}$mast cells in response to KitL, we provide genetic evidence that activation of the class $1_{\mathrm{A}}$-PI3K-Rac2 pathway is directly responsible for the increased migration of $\mathrm{Nf1}^{+/-}$mast cells. This is an important observation since we have previously shown that increased activation of this signaling pathway is also responsible for the increased proliferation and survival of $\mathrm{Nf1}^{+/-}$mast cells (13). Thus, the recruitment and expansion of mast cell numbers within neurofibromas may be mediated through a common series of Ras effector targets.

A major effort in our lab and others is now focused on formally testing the specific contribution of each $\mathrm{Nf1}^{+/-}$ cell lineage identified within the tumor microenvironment to neurofibroma formation. It is possible that other cells within the tumor microenvironment (particularly endothelial cells and fibroblasts), through paracrine interactions with mast cells and/ or Schwann cells, may contribute to the tumor progression of neurofibromas. Understanding the complex interaction between these cell types within the tumor is an important component of these studies. In addition, the tumors that have been observed in the murine model to date have been plexiform neurofibromas derived from DRG and cranial nerves. Whether this is a consequence of the expression pattern of the Cre transgene used in those experiments or alternatively reflects a slightly different pathogenesis from the benign cutaneous neurofibromas remains an important question. It is reasonable to speculate based on the existing evidence linking inflammation to tumorigenesis that reduction of mast cell infiltration into neurofibromas may result in decreased growth or occurrence. If this is the case, our studies provide several attractive therapeutic targets including inhibition of c-kit activity and adhesion to $\alpha_{4} \beta_{1}$. Imatinib mesylate is currently being used to treat patients with chronic myelogenous leukemia and gastrointestinal tumors where c-kit activation is central to the disease pathogenesis (52). Furthermore, drugs targeting $\alpha_{4} \beta_{1}$ activation are currently being tested in clinical trials to treat multiple sclerosis and Crohn disease where inflammatory cell recruitment to both the CNS and gastrointestinal tract by adhesion to $\alpha_{4} \beta_{1}$ is thought to be important for disease progression (53-55). Based on our work, these treatments may be potentially useful in treating or preventing neurofibroma formation in NF1 patients. In addition, pharmacologic inhibition of PI3K or the hematopoietic-specific small Rho GTPase, Rac2, may decrease mast cell numbers within neurofibromas.

\section{Acknowledgments}

We thank Kevin Shannon for reading this manuscript and Marsha Hippensteel for administrative support. This work was supported by National Cancer Institute grants 1 KO8 CA096579-01 (to D.A. Ingram), 2 RO1 CA74177-06 (to D.W. Clapp), NIDDK grant P30 DK49218 (to D.W. Clapp and D.A. Ingram), Department of Defense grant DAMD17-01-1-0711 (to D.A. Ingram and D.W. Clapp), National Heart, Lung, and Blood Institute grant P01 HL069974 (to D.W. Clapp and S. Atkinson), Department of Defense grant NF020026 (D.W. Clapp, D.A. Ingram, and F.-C. Yang), NIH grants NS-28840 (to N. Ratner), T32-CA-59268 (to K.R. Monk), and R01 2DK486-05 (to D.A. Williams). D.A. Ingram is a recipient of a Basil O'Connor Award from the March of Dimes (5-FY02-254).

1. Riccardi, V.M. 1981. Cutaneous manifestation of neurofibromatosis: cellular interaction, pigmentation, and mast cells. Birth Defects Orig. Artic. Ser. 17:129-145.

2. Viskochil, D., et al. 1990. Deletions and a translocation interrupt a cloned gene at the neurofibromatosis type 1 locus. Cell. 62:187-192.

3. Wallace, M.R., et al. 1990. Type 1 neurofibromatosis gene: identification of a large transcript disrupted in three NF1 patients. Science. 249:181-186.

4. Cichowski, K., and Jacks, T. 2001. NF1 tumor suppressor gene function: narrowing the GAP. Cell. 104:593-604.

5. McLaughlin, M.E., and Jacks, T. 2002. Thinking beyond the tumor cell: Nf1 haploinsufficiency in the tumor environment. Cancer Cell. 1:408-410.

6. Hirota, S., et al. 1993. Possible involvement of c-kit receptor and its ligand in increase of mast cells in neurofibroma tissues. Arch. Pathol. Lab. Med. 117:996-999.

7. Johnson, M., Kamso-Pratt, J., Federspiel, C.F., and Whetsell, W.O., Jr. 1990. Mast cell and lymphoreticular infiltrates in neurofibromas. Comparison with nerve sheath tumors. Arch. Pathol. Lab. Med. 114:191-192.

8. Zhu, Y., Ghosh, P., Charnay, P., Burns, D.K., and Parada, L.F. 2002. Neurofibromas in NF1: Schwann cell origin and role of tumor environment. Science. 296:920-922.

9. Hanahan, D., and Weinberg, R.A. 2000. The hallmarks of cancer. Cell. 100:57-70.

10. Coussens, L.M., and Werb, Z. 2001. Inflammatory cells and cancer: think different! J. Exp. Med. 193:F23-F26.

11. Coussens, L.M., and Werb, Z. 2002. Inflammation and cancer. Nature. 420:860-867.

12. Ingram, D.A., et al. 2000. Genetic and biochemical evidence that haploinsufficiency of the Nf1 tumor suppressor gene modulates melanocyte and mast cell fates in vivo. J. Exp. Med. 191:181-188.

13. Ingram, D.A., et al. 2001. Hyperactivation of $\mathrm{p} 21$ ras and the hematopoietic-specific Rho GTPase, Rac2, cooperate to alter the proliferation of neurofibromin deficient mast cells in vivo and in vitro. J. Exp. Med. 194:57-70.

14. Ryan, J.J., et al. 1994. Role for the stem cell factor/KIT complex in Schwann cell neoplasia and mast cell proliferation associated with neurofibromatosis. J. Neurosci. Res. 37:415-432.

15. Coussens, L.M., et al. 1999. Inflammatory mast cells up-regulate angiogenesis during squamous epithelial carcinogenesis. Genes. Dev. 13:1382-1397.

16. Coussens, L.M., Tinkle, C.L., Hanahan, D., and Werb, Z. 2000. MMP-9 supplied by bone marrow-derived cells contributes to skin carcinogenesis. Cell. 103:481-490.

17. Bergers, G., et al. 2000. Matrix metalloproteinase- 9 triggers the angiogenic switch during carcinogenesis. Nat. Cell Biol. 2:737-744.

18. Leon, A., et al. 1994. Mast cells synthesize, store and release nerve growth factor. Proc. Natl. Acad. Sci. U. S. A. 91:3739-3743.

19. Boesiger, J., et al. 1998. Mast cells can secrete vascular permeability factor/vascular endothelial cell growth factor and exhibit enhanced release after immunoglobulin E-dependent upregulation of fc epsilon receptor I expression. J. Exp. Med. 188:1135-1145.

20. Sondell, M., Lundborg, G., and Kanje, M. 1999. Vascular endothelial growth factor has neurotrophic activity and stimulates axonal outgrowth, enhancing cell survival and Schwann cell proliferation in the peripheral nervous system. J. Neurosci. 19:5731-5740.

21. Schratzberger, P., et al. 2000. Favorable effect of VEGF gene transfer on ischemic peripheral neuropathy. Nat. Med. 6:405-413. 
22. Jacks, T., et al. 1994. Tumour predisposition in mice heterozygous for a targeted mutation in NF1. Nat. Genet. 7:353-361.

23. Roberts, A.W., et al. 1999. Deficiency of the hematopoietic cell-specific Rho family GTPase Rac2 is characterized by abnormalities in neutrophil function and host defense. Immunity. 10:183-196.

24. Cantley, L.C., and Neel, B.G. 1999. New insights into tumor suppression: PTEN suppresses tumor formation by restraining the phosphoinositide 3-kinase/AKT pathway. Proc. Natl. Acad. Sci. U. S. A. 96:4240-4245.

25. Valchanov, K.P., and Proctor, G.B. 1999. Enzyme histochemistry of tryptase in stomach mucosal mast cells of the mouse. J. Histochem. Cytochem. 47:617-622.

26. Kim, H.A., Ling, B., and Ratner, N. 1997. Nf1-deficient mouse Schwann cells are angiogenic and invasive and can be induced to hyperproliferate: reversion of some phenotypes by an inhibitor of Farnesyl protein transferase. Mol. Cell Biol. 17:862-872.

27. Hiatt, K., Ingram, D.A., Zhang, Y., Bollag, G., and Clapp, D.W. 2001. Neurofibromin GTPase-activating protein-related domains restore normal growth in Nf1-/- cells. J. Biol. Chem. 276:7240-7245.

28. Klose, A., et al. 1998. Selective disactivation of neurofibromin GAP activity in neurofibromatosis type 1 (NF1). Hum. Mol. Genet. 7:1261-1268.

29. Tan, B., et al. 2003. Genetic evidence for convergence of c-Kit- and alpha4 integrin-mediated signals on class IA PI-3kinase and the Rac pathway in regulating integrin-directed migration in mast cells. Blood. 101:4725-4732.

30. Yang, F.C., et al. 2001. Rac and Cdc42 GTPases control hematopoietic stem cell shape, adhesion, migration, and mobilization. Proc. Natl. Acad. Sci.U. S. A. 98:5614-5618.

31. Webb, D.J., Parsons, J.T., and Horwitz, A.F. 2002. Adhesion assembly, disassembly and turnover in migrating cells-over and over and over again. Nat. Cell Biol. 4:E97-E100.

32. Yang, J.T., Rayburn, H., and Hynes, R.O. 1995. Cell adhesion events mediated by alpha4 integrins are essential in placental and cardiac development. Development. 121:549-560.

33. Arroyo, A.G., Yang, J.T., Rayburn, H., and Hynes, R.O. 1996. Differential requirements for alpha 4 integrins during fetal and adult hematopoiesis. Cell. 85:997-1008.

34. Zou, J.X., et al. 1999. An Eph receptor regulates integrin activity through R-Ras. Proc. Natl. Acad. Sci. U. S. A. 96:13813-13818.

35. Hughes, P.E., et al. 1997. Suppression of integrin activation: a novel function of a Ras/Raf-initiated MAP kinase pathway. Cell. 88:521-530.

36. Kinashi, T., et al. 2000. Distinct mechanisms of alpha5beta 1 integrin activation by Ha-Ras and R-Ras. J. Biol. Chem. 275:22590-22596.

37. Brakebusch, C., Bouvard, D., Stanchi, F., Sakai, T., and Fassler, R. 2002. Integrins in invasive growth. J. Clin. Invest. 109:999-1006. doi:10.1172/ JCI200215468

38. Zhang, Z., Vuori, K., Wang, H., Reed, J.C., and Ruoslahti, E. 1996. Integrin activation by R-Ras. Cell. 85:61-69.
39. Shibayama, H., et al. 1999. H-Ras is involved in the inside-out signaling pathway of interleukin-3-induced integrin activation. Blood. 93:1540-1548.

40. Keely, P.J., Rusyn, E.V., Cox, A.D., and Parise, L.V. 1999. R-Ras signals through specific integrin alpha cytoplasmic domains to promote migration and invasion of breast epithelial cells. J. Cell Biol. 145:1077-1088.

41. Bollag, G., and McCormick, F. 1992. NF is enough of GAP. Nature. 356:663.

42. Lu-Kuo, J.M., Fruman, D.A., Joyal, D.M., Cantley, L.C., and Katz, H.R. 2000. Impaired kit- but not FcepsilonRI-initiated mast cell activation in the absence of phosphoinositide 3-kinase p85alpha gene products. J. Biol. Chem. 275:6022-6029.

43. Yang, F.-C., et al. 2000. Rac2 stimulates Akt activation affecting $\mathrm{BAD} / \mathrm{Bcl}-\mathrm{XL}$ expression while mediating survival and actin function in primary mast cells. Immunity. 12:557-568.

44. Gurish, M.F., et al. 2001. Intestinal mast cell progenitors require CD49dbeta7 (alpha4beta7 integrin) for tissue-specific homing. J. Exp. Med. 194:1243-1252.

45. Badache, A., Muja, N., and De Vries, G.H. 1998. Expression of Kit in neurofibromin-deficient human Schwann cells: role in Schwann cell hyperplasia associated with type 1 neurofibromatosis. Oncogene. 17:795-800.

46. Donovan, S., See, W., Bonifas, J., Stokoe, D., and Shannon, K.M. 2002 Hyperactivation of protein kinase B and ERK have discrete effects on survival, proliferation, and cytokine expression in Nf1-deficient myeloid cells. Cancer Cell. 2:507-514.

47. Birnbaum, R.A., et al. 2000. Nf1 and Gmcsf interact in myeloid leukemogenesis. Mol. Cell. 5:189-195.

48. Arbiser, J.L., Flynn, E., and Barnhill, R.L. 1998. Analysis of vascularity of human neurofibromas. J. Am. Acad. Dermatol. 38:950-954.

49. Mierke, C.T., et al. 2000. Human endothelial cells regulate survival and proliferation of human mast cells. J. Exp. Med. 192:801-812.

50. Heissig, B., et al. 2002. Recruitment of stem and progenitor cells from the bone marrow niche requires MMP-9 mediated release of kit-ligand Cell. 109:625-637.

51. Boyce, J.A., Mellor, E.A., Perkins, B., Lim, Y.C., and Luscinskas, F.W. 2002 Human mast cell progenitors use alpha4-integrin, VCAM-1, and PSGL-1 E-selectin for adhesive interactions with human vascular endothelium under flow conditions. Blood. 99:2890-2896.

52. Druker, B.J. 2002. Perspectives on the development of a molecularly targeted agent. Cancer Cell. 1:31-36.

53. Miller, D.H., et al. 2003. A controlled trial of natalizumab for relapsing multiple sclerosis. N. Engl. J. Med. 348:15-23.

54. Ghosh, S., et al. 2003. Natalizumab for active Crohn's disease. N. Engl. J. Med. 348:24-32

55. von Andrian, U.H., and Engelhardt, B. 2003. Alpha4 integrins as therapeutic targets in autoimmune disease. N. Engl. J. Med. 348:68-72. 